\title{
El diseño universal en la interfaz gráfica de multimedia educativo
}

Universal design in the graphic interface of educational multimedia

\section{Volumen 17, Número 3 \\ Setiembre-Diciembre}

pp. 1-19

Este número se publica el $1^{\circ}$ de setiembre de 2017

DOI: https://doi.org/10.15517/aie.v17i3.30207

\author{
Juan Diego Delgado Vargas
}

Revista indizada en REDALYC, $\underline{\text { SCIELO }}$

Revista distribuida en las bases de datos:

LATINDEX, DOAJ, REDIB, IRESIE, CLASE, DIALNET, SHERPA/ROMEO, QUALIS-CAPES, MIAR

Revista registrada en los directorios:

ULRICH'S, $\underline{\text { REDIE}}, \underline{\text { RINACE}}, \underline{\text { OEI }}, \underline{\text { MAESTROTECA }}, \underline{\text { PREAL, }} \underline{\text { CLACSO }}$ 


\title{
El diseño universal en la interfaz gráfica de multimedia educativo
}

\author{
Universal design in the graphic interface of educational multimedia
}

\section{Juan Diego Delgado Vargas ${ }^{1}$}

\begin{abstract}
Resumen: El presente ensayo expone la aplicación del diseño universal en la interfaz gráfica del multimedia educativo elaborado bajo el concepto de Laboratorio virtual, proyecto de investigación que forma parte del Acuerdo de Mejoramiento Institucional (AMI) de la Universidad Estatal a Distancia (UNED) de Costa Rica. Para ello, se presentan referentes teóricos para su fundamentación, los cuales contribuyen con una reflexión acerca de la temática a partir de la experiencia del Programa de Producción Electrónica Multimedial (PEM) en esta área, como parte de una revisión de sus procesos productivos y oferta de este tipo de materiales. El diseño de la interfaz gráfica implica, por ende, valorar la necesidad del diseño universal aplicado a la elaboración de materiales didácticos, con especial énfasis en aquellos con salida digital, ya que por su naturaleza involucran la elaboración de entornos gráficos que deben ser accesibles, por lo tanto, la UNED debe considerar a través de la Dirección de Producción de Materiales Didácticos (DPMD) y sus diferentes instancias, propuestas como esta, que evidencian el esfuerzo y compromiso por incorporar nuevas metodologías de diseño que contribuyan al mejoramiento de la accesibilidad y la inclusión de sus materiales orientados a educación a distancia.
\end{abstract}

Palabras clave: enseñanza multimedia, método de enseñanza, formación, material didáctico.

Abstract: The current essay has the main goal of presenting Universal Design applied to the graphical user interface of the educational multimedia resources developed under the concept of Virtual Laboratory, research project of Acuerdo de Mejoramiento Institucional (AMI), of Universidad Estatal a Distancia (UNED) of Costa Rica. For this purpose, different theories and concepts are introduced, along with reflexions about the contributions and experiences by Programa de Producción Electrónica Multimedial (PEM) in this field, as part of a review of their productive processes and deliver instructional resources in distance education. The design of the graphic interface implies assessing the need for Universal Design applied to the creation of teaching materials, with especial emphasis on those with digital output, since by their nature they involve the development of graphical environment that must be accessible, therefore, UNED must consider through the Dirección de Producción de Materiales Didácticos (DPMD) and their different instances proposals such as this, that shows the hard work and commitment by incorporating new design methodologies that contribute to the improvement of accessibility and the inclusion of their resources in distance education oriented materials.

Key words: multimedia teaching, teaching method, training, teaching material.

\footnotetext{
1 Productor $y$ diseñador gráfico en multimedia educativo en el Programa de Producción Electrónica Multimedial (PEM) de la Universidad Estatal a Distancia (UNED) de Costa Rica.
}

Dirección electrónica: jdelgadov@uned.ac.cr

Ensayo recibido: 19 de octubre, 2016

Enviado a corrección: 9 de mayo, 2017

Aprobado: 14 de agosto, 2017 


\section{Introducción}

Este ensayo presenta un recorrido teórico por el diseño universal aplicado en la elaboración de la interfaz gráfica del multimedia educativo producido bajo el concepto de laboratorio virtual, cuyo proyecto de investigación es parte de las acciones desarrolladas en la iniciativa 8 y sub-iniciativa 4 del Acuerdo de Mejoramiento Institucional (AMI) de la Universidad Estatal a Distancia (UNED) de Costa Rica, desarrollado a través del Plan de Mejoramiento Institucional (PMI) que se originó en el marco de las negociaciones del Fondo Especial para el Financiamiento de la Educación Superior Estatal (FEES) en el año 2012.

El Programa de Producción Electrónica Multimedial (PEM), de la Dirección de Producción de Materiales Didácticos (DPMD), es el encargado de elaborar dichos materiales dirigidos a estudiantes del sistema de educación superior a distancia, que utilizan las TIC como apoyo en sus procesos de enseñanza-aprendizaje. Para ello, se exponen referentes teóricos, se definen conceptos importantes y, por último, se valoran los aportes del programa en este campo.

Es importante considerar que la producción de esos materiales didácticos es un proceso interdisciplinario y colaborativo en el que los profesionales involucrados aportan desde sus áreas de experticia, con base en los objetivos educativos y el público meta.

Además, el componente del diseño gráfico es uno de los elementos mediadores del proceso de comunicación entre el contenido y el estudiante, al cual se le ha dedicado estudio e investigación. Esto se evidencia en el diseño de interfaces gráficas en las cuales la metáfora pedagógica continúa siendo predominante; sin embargo, su evolución, producto de las nuevas tecnologías y sus posibilidades en variados medios, obligan a considerar el aporte de otras metodologías como el diseño universal y el adaptativo en la producción de multimedia educativo.

\section{Diseño Universal}

En el año 1974, durante la reunión de un grupo de expertos sobre el diseño libre de barreras, celebrada en la ciudad de Nueva York, Estados Unidos, surgió el tema de adaptar el medio físico a las personas con algún tipo de discapacidad, con el propósito de darles acceso, en igualdad de condiciones, a la sociedad. Este acceso se haría con el menor número de obstáculos posible, mediante la eliminación de barreras, concepto comúnmente relacionado con la construcción de espacios físicos de fácil acceso, como por ejemplo 
rampas y ascensores, pero hoy en día, es aplicable a áreas profesionales diferentes a la arquitectura y el paisajismo.

Con el tiempo se fue haciendo evidente que este tipo de construcciones eran una ayuda técnica que le permitía a las personas con necesidades especiales insertarse de mejor manera en la dinámica social, les brindaba la posibilidad de desempeñar funciones en su vida cotidiana y, en algunos casos, más bien potenciaba sus capacidades y desempeño al relacionar los términos de flexibilidad y accesibilidad. Gracias a esta relación, la accesibilidad hoy se mira de forma diferente y más amplia, pues aquello accesible para las personas con algún tipo de discapacidad es también funcional para todos los demás.

Después de dicha reunión, surge el paradigma del diseño universal, corriente teórica que tiene sus orígenes en el funcionalismo escandinavo de los años 50 y en el diseño ergonómico de los años 60, así como en la política social sueca de finales de los años 70 , donde nació el concepto de una sociedad para todos, con lo cual se poníaespecial énfasis en el término de accesibilidad (Observatorio de la Accesibilidad, s.f.).

Ronald L. Mace, arquitecto y fundador del Centro para el Diseño Universal, mencionado por Bibiana Misischia en su artículo Supresión de barreras en la universidad, lo define como "la creación de productos y entornos diseñados de modo que sean utilizables por todas las personas en la mayor medida posible, sin necesidad de adaptaciones 0 diseños especializados" (2013, párr.1). Este término fue aprobado oficialmente en el año 2006 por la Convención de Naciones Unidas sobre los Derechos de las Personas con Discapacidad, en el artículo número 2.

En otras palabras, el diseño universal busca la creación de entornos y productos con un proceso planificado de elaboración para que sean utilizados por la mayor cantidad de personas sin distinción alguna (en edad y capacidades), mediante una serie de principios que permiten guiar y evaluar el diseño, así como educar a los diseñadores sobre las características que deben tener para que sean más accesibles al valorar la diversidad y la inclusión.

Este proceso se aplica en diferentes áreas como la arquitectura, el paisajismo, la ingeniería, la comunicación y el diseño industrial. Estas tres últimas, al interactuar con otras disciplinas del diseño (gráfico, web, software y de ergonomía) permiten la creación de la interfaz gráfica. 


\subsection{Principios del diseño universal}

El Centro para el Diseño Universal (1997 citado por la Fundación SIDAR, 2007), traduce los principios a considerar, en este tema, de la siguiente manera:

1) Uso equiparable. Es útil y vendible a personas con diversas capacidades.

2) Uso flexible. Se acomoda a un amplio rango de preferencias y habilidades individuales.

3) Simple e intuitivo. Su uso es fácil de entender, atiende a la experiencia, conocimientos, habilidades lingüísticas o grado de concentración actual del usuario.

4) Información perceptible. Comunica de manera eficaz la información necesaria para el usuario y pone atención a las condiciones ambientales o a las capacidades sensoriales del usuario.

5) Con tolerancia al error. Minimiza los riesgos y las consecuencias adversas de acciones involuntarias o accidentales.

6) Que exija poco esfuerzo físico. Puede ser usado eficaz y confortablemente y con un mínimo de fatiga.

7) Tamaño y espacio para el acceso y uso. Proporciona un tamaño y espacio apropiados para el acceso, alcance, manipulación y uso, y contempla el tamaño del cuerpo, la postura o la movilidad del usuario.

Con base en lo anterior, es importante mencionar que el proceso de diseño, a través de estas pautas, evidencia un sentimiento de responsabilidad en cuanto a la inclusión de la mayor diversidad de usuarios posible. Además, es necesario considerar una etapa de investigación de usuarios para conocer y considerar sus características como necesidades, ya que de ellos depende el impacto que puede tener lo que se diseñe.

En el ámbito de la educación, el diseño universal actualmente tiene una gran influencia en las políticas y metodologías educativas de diferentes países donde se integra de manera formal en los procesos de educación inclusiva, y en la UNED de Costa Rica esto no ha pasado desapercibido. En los últimos años se han venido desarrollando diferentes iniciativas para promover su uso y principales enfoques, como por ejemplo el diseño universal en educación, desarrollado por el DO-IT Center (Discapacidades, Oportunidades, Interconexión de redes y Tecnología por sus siglas en inglés) de la Universidad de Washington en los Estados Unidos. 
Sheryl Burgstahler, directora y fundadora del DO-IT Center, define este enfoque como “...un marco filosófico para diseñar un rango general de productos y ambientes educativos" (2007, párr. 2). De este modo, no solo se centra en el diseño de los currículos, sino que, por su concepción más amplia, también analiza otros factores, como por ejemplo software educativo y sitios web, entre otros recursos que se pueden considerar materiales didácticos con componente tecnológico.

\section{Diseño gráfico}

Paul Rand, diseñador gráfico y profesor en la Universidad de Yale, define el diseño gráfico en su libro Design Form and Chaos como:

entender el significado del diseño no es sólo entender el papel que desempeñan la forma y el contenido, sino descubrir que el diseño es también un comentario, una opinión, un punto de vista y una responsabilidad social. Diseñar es mucho más que simplemente ensamblar, ordenar, incluso editar: es añadir valor y significado, iluminar, simplificar, aclarar, modificar, teatralizar, persuadir y, quizá, incluso entretener. (2007, p. 6)

Lo anterior apoya el hecho de que el diseño gráfico es algo más que un simple conjunto de imágenes y texto con énfasis en la composición y la estética, es un elemento visual comunicativo interpretado en un mensaje por medio de diferentes elementos tangibles (imágenes, formas, colores) y otros intangibles (sensaciones, percepciones y sentimientos).

Algunos de los elementos que influyen en la forma en que se transmite un mensaje y que deben tomarse en consideración, al trabajar en diseño gráfico, son los siguientes:

- El color: las primeras evidencias de su uso datan desde la época de la prehistoria, cuando se realizaron las primeras manifestaciones de arte mediante el color rojo desprendido de las tierras arcillosas. En la actualidad, Morton (2010) menciona que los estudios realizados por el Institute of Color Research evidencian que:

[...] las personas realizan juicios subconscientes de un ambiente, de un producto o una persona dentro de los 90 segundos de visualización inicial y que entre el 62 y el 90 por ciento de ese juicio se basa solo en el color. (párr. 4)

Podría decirse que el color es uno de los elementos clave en una composición gráfica, ya que contribuye a transmitir sensaciones, percepciones y sentimientos en la interpretación 
de un mensaje. Así lo referencian Velasco, Laureano, Mora y Herrera (2010), quienes afirman que:

[...] el color es un elemento clave en el diseño gráfico, es el elemento más visible en un servicio o producto. Antes de iniciar la lectura de un texto o comprender una imagen, el color ya empieza a transmitirnos su mensaje. (Sección Psicología del color, párr. 1)

- La tipografía: con la invención de la imprenta, en la época del Renacimiento, la tipografía toma relevancia de la mano de figuras importantes en su historia como Stanley Morison (1929), citado por Gutiérrez (2012), quien definió la tipografía como:

[...] el arte de disponer correctamente el material de imprimir, de acuerdo con un propósito específico: el de colocar las letras, repartir el espacio y organizar los tipos con vistas a prestar al lector la máxima ayuda para la comprensión del texto escrito verbalmente. (párr. 1)

Puede considerarse entonces, la tipografía como una expresión gráfica de la voz que contribuye a transmitir el mensaje; por ello, es importante cuando se utiliza, pensar en el público al que va dirigido, ya que este debe tener la capacidad de leerlo y comprenderlo sin ningún tipo de obstáculo o niveles de dificultad posibles.

- La imagen: según el diccionario de la Real Academia Española la palabra imagen proviene del latín imago que significa figura, representación, semejanza y apariencia de algo. Fornasari de Menegazzo va más allá de lo simple y la define como "toda representación visual que mantiene una relación de semejanza con el objetivo de ser representado" (1994, p. 21).

Una imagen es, entonces, un elemento meramente visual que se utiliza para representar objetos, sujetos o situaciones ficticias o reales, que evocan expresiones y sentimientos para transmitir un mensaje. Es un elemento comunicacional de la gráfica visual.

- La composición: se entiende como la organización de varios elementos gráficos dentro del espacio visual que, combinados, tienen la capacidad de aportar un significado a la transmisión de un mensaje. Es decir, la composición distribuye los diferentes elementos en una composición gráfica (color, tipografía, imagen) de forma equilibrada que da sentido a la transmisión de un mensaje. Al respecto Gillian (1980) en su libro Fundamentos del diseño 
manifiesta que "la composición significa también organización estructural y que esta constituye el fundamento de las relaciones visuales" (p.19).

La composición es por lo tanto importante, ya que, mediante propiedades como: orden, balance, unidad y relación entre los elementos gráficos en su conjunto, permite transmitir el mensaje de forma concreta facilitando su comprensión por parte del público al cual se orientó.

\section{Metáfora pedagógica}

Luis Fernando Díaz, productor académico de la UNED de Costa Rica, la define como (...) un elemento comunicativo, usualmente gráfico, a veces animado, que trasmite en forma sucinta y reiterada el mensaje educativo central del multimedio o del objeto específico. Provee unidad gráfica (y refuerza la unidad pedagógica) en el diseño de todo el material y no solo en pantallas aisladas o en hipervínculos. (2011, párr. 6)

Es decir, está metodología permite fortalecer y favorecer, mediante la reiteración del mensaje y los contenidos educativos, el aprendizaje que, de forma simultánea, se comunica mediante otras formas semánticas; y por lo tanto debe ser un proceso planificado desde el diseño mismo.

En los multimedia educativos, su concreción se origina dentro de una etapa creativa, propia del proceso de producción, caracterizada por la elaboración de una propuesta pedagógica que, además de mediar los contenidos, es representada gráficamente para favorecer el nexo motivacional y de interés por explorar los contenidos, e interartuar con estos a través de la interfaz. En la elaboración de la interfaz gráfica este concepto orienta el diseño de los elementos que la conforman, como por ejemplo, la interfaz principal, secundarias, recursos multimedia y de navegación, tales comomenús, botones e íconos.

Díaz (2011) destaca 7 aspectos pedagógicos que dan valor a la metáfora en la producción de materiales didácticos:

1) Trasmite en forma sucinta y reiterada el mensaje educativo central.

2) Fortalece el aprendizaje por cuanto reitera con otros recursos el mensaje textual. Parte de su valor formativo consiste en que refuerza, mediante la repetición, el mensaje y los contenidos, al aprendizaje y a la internalización de los conocimientos, los valores y las conductas que, simultáneamente, se comunican mediante otros lenguajes. 
3) Facilita la construcción y la presentación de índices, menús y botoneras para la navegación dentro del multimedia. Formas simplificadas de la metáfora (hojas, lápices de color, flechas) permiten a los lectores distinguir textos vinculados con el mensaje principal, pero que obedecen a finalidades distintas del dominio de contenidos por aprender. Esta economía de representación resulta en un ahorro de energía en las actividades educativas, particularmente en la auto-instrucción.

4) En ese mismo sentido, propicia la construcción de familias de iconos aplicables incluso a los materiales impresos, con la intención de facilitar el desplazamiento del estudiante por el texto a través de instrucciones tanto gráficas como verbales.

5) Favorece la identificación de los usuarios porque mueve sus emociones y sus sentimientos, crea empatía y complicidad, lo que favorece la exploración y el uso de los materiales por el estudiantado.

6) Modera la frialdad implícita en la comunicación vía máquinas y medios electrónicos, sin dejar de atender a la veracidad y la verosimilitud. Igual efecto provoca en los voluminosos textos tradicionales impresos en blanco y negro.

7) Es un recurso de calidad. Una buena metáfora permea y orienta toda la producción, se reproduce y se enriquece a sí misma y concentra la atención de los usuarios. En este rol, se espera de ella un efecto multiplicador sobre el aprendizaje.

\section{Interfaz gráfica}

Ben Shneiderman, catedrático en Informática de la Universidad de Maryland en Estados Unidos define la interfaz como "la membrana de comunicación entre los usuarios y el sistema por la que los diseñadores y desarrolladores de herramientas informáticas pueden hacer que la tecnología sea inteligible y sensible a las necesidades de los usuarios" (1998, p. 4).

En este caso en particular, la interfaz gráfica se puede considerar un mediador visual que facilita la comunicación fluida y clara entre un sistema y el usuario para facilitar su comprensión y uso. Esta, por lo general, se manifiesta en un entorno gráfico compuesto principalmente de imágenes y objetos para representar la información y las acciones disponibles para ejecutar.

Shneiderman (1998 mencionado por Mañas, 2011, pp. 27-34), enlista 8 reglas de oro del diseño de interfaces: 
1) Esforzarse para conseguir consistencia: exigir secuencias de acciones consistentes; utilizar terminología coherente en los mensajes, menús y pantallas de ayuda; emplear de forma consistente el color, la composición, las mayúsculas, las fuentes y otros elementos similares. Las excepciones, como la necesaria confirmación de la orden de borrado o no mostrar los caracteres de las contraseñas, deberían ser comprensibles y limitadas en número.

2) Atender la usabilidad universal: reconocer las necesidades de los diversos usuarios, así como las diferencias entre ellos (principiante o experto, edades, discapacidades y diversidad tecnológica), para facilitar la transformación del contenido.

3) Ofrecer realimentación informativa: incluir para cada acción del sistema una realimentación por parte del sistema.

4) Diseñar diálogos para conducir a la finalización: crear sistemas claros de conducción hasta el final del proceso de las secuencias de acción del usuario.

5) Prevenir errores: diseñar el sistema de forma que los usuarios no puedan cometer errores serios.

6) Permitir deshacer acciones de forma fácil: tener la posibilidad de remediar acciones erróneas; por lo tanto, construir un sistema reversible. Este sistema suaviza la ansiedad que se puede producir en el usuario.

7) Dar soporte al control interno: ofrecer a los operadores experimentados la sensación de controlar la interfaz y que esta responde a sus acciones. Las acciones sorprendentes por parte de la interfaz, las secuencias de entrada de datos tediosas, la incapacidad o dificultad para obtener la información necesaria y la incapacidad para producir acciones deseadas crean ansiedad e insatisfacción.

8) Reducir la carga de la memoria a corto plazo: diseñar sistemas de visualización simples, que la frecuencia de movimiento de ventana se reduzca y que se asigne suficiente tiempo de entrenamiento para códigos y secuencias de acciones.

Como consecuencia, un buen diseño de interfaz gráfica no solo se centra en la parte visual, su estética y la composición, sino también en el desarrollo de su interacción a través de las reglas anteriormente mencionadas. Ambos aspectos se complementan, ya que en gran medida determinan la buena experiencia de uso por parte del usuario. 


\section{Diseño adaptativo}

Sin duda alguna el siglo XXI se ha caracterizado por el uso cada vez más frecuente y cotidiano de dispositivos móviles como tabletas, teléfonos inteligentes y computadoras portátiles, entre otros. Según las Directrices para las políticas de aprendizaje móvil de la Unesco (Organización de las Naciones Unidas para la Educación, la Ciencia y la Cultura):

Hay en el mundo más de 3.200 millones de usuarios registrados con teléfonos móviles, lo que hace de estos dispositivos la modalidad de TIC más utilizada en la Tierra. En los países desarrollados, 4 de cada 5 personas poseen y utilizan un teléfono móvil y, aunque la tasa es significativamente más baja que en los países en desarrollo (2 de cada 5), es en estos países donde se registra el crecimiento más rápido en cuanto a índice de penetración en el mercado. (2013, p. 7)

En el contexto educativo este fenómeno no ha pasado desapercibido, los y las estudiantes de diferentes modelos educativos en el mundo utilizan estos dispositivos con diferentes objetivos, como gestión administrativa, comunicación y en procesos de enseñanza-aprendizaje. Según las Directrices para las políticas de aprendizaje móvil de la Unesco se cree al respecto que:

[...] las tecnologías móviles pueden ampliar y enriquecer las oportunidades educativas en distintos contextos. Hay cada vez más datos que indican que los omnipresentes dispositivos móviles, en particular los teléfonos móviles y, más recientemente, las tabletas, son utilizados por educandos y docentes de todo el mundo para acceder a información, simplificar la administración y facilitar el aprendizaje de una forma nueva e innovadora. $(2013$, p.5)

En el caso particular de la UNED de Costa Rica, según un estudio realizado en el año 2014 por Salazar, Berrocal, Salas y Valerio, en el que se consideró la respuesta de 877 estudiantes y 211 tutores representativos de las instancias académicas de la universidad, el $90 \%$ afirmó poseer un teléfono móvil, de los cuales $63,3 \%$ son teléfonos inteligentes; un $30 \%$ son tabletas y un $42 \%$ son reproductores de audio y video.

A partir de dicha información, se generó una reflexión respecto a la forma en que los usuarios (especialmente estudiantes) pueden utilizar los materiales didácticos, además de un análisis en cuanto a la presentación de contenidos y reestructuración del proceso de producción de quienes los llevan a cabo; y es así como el diseño adaptativo surge como una 
posible respuesta a la necesidad de que dichos materiales estén disponibles para dispositivos móviles con el propósito de que estos no queden fuera del contexto actual.

El diseñador Manuel Rubio en su artículo ¿Qué es Diseño Adaptativo? lo define como "[...] una técnica de diseño y desarrollo web que mediante el uso de estructuras e imágenes fluidas, así como de media-queries en las hojas de estilo CSS, se consigue adaptar el sitio web al dispositivo del usuario" (2013, párr. 1). Esta adaptación implica que la interfaz gráfica, así como los contenidos educativos desarrollados para un material didáctico de la Universidad, se ajustan según la resolución de la pantalla sin importar el tipo de dispositivo desde el que se accede, pero, en ningún caso (a menos que así se contemple) significa el sacrificio de contenido para cumplir tal propósito. Así, tanto la información escrita apoyada de imágenes, videos, animaciones, actividades, entre otros recursos son adaptados.

\section{Elección de diseño adaptativo}

El diseño adaptativo es una metodología de diseño que permite una mayor universalización de los contenidos de un material en específico, pero la elección de este tipo de diseño no debe recaer simplemente en la versatilidad de producción, sino que su implementación debe cumplir criterios de producción para que sea efectivo, de lo contrario sería mejor optar por otro tipo de soluciones.

Se debe procurar que la adaptación de los materiales sea tal, que el usuario no tenga problemas en determinar el cambio, máxime cuando se trabaja en coordinación con otras estrategias didácticas. Si bien es cierto, el desarrollo de diseño adaptativo ahorra tiempo si se le compara con la producción de una versión según dispositivo, se debe contemplar el hecho de que la programación necesaria para elaborar un material de este tipo es compleja y debe estar muy bien planificada.

Aunque en la actualidad se habla de una mayor penetración de las tecnologías móviles en el mundo, antes de implementarlo con un propósito didáctico, se debe revisar el nivel de utilización potencial que los usuarios del material hacen de sus dispositivos móviles, de manera que se pueda valorar a futuro la idoneidad de la puesta en marcha de la implementación de este tipo de diseño.

\section{Aportes y experiencias del PEM en la producción de multimedia educativo}

EI PEM ha desarrollado multimedias educativos desde su creación en el año 2000. La consigna de producción académica es buscar e implementar en ellos la mejor combinación 
posible de mediación de contenidos y uso de las TIC en beneficio del estudiantado a partir de criterios pedagógicos y de diseño. En este mismo espíritu de observar y analizar los cambios que se dan a nivel educativo con respecto a las diferentes posibilidades tecnológicas, es que el PEM comenzó su incursión en el uso del diseño adaptativo en la producción de multimedia educativo, a partir del uso de herramientas y disposiciones conceptuales para obtener materiales didácticos más inclusivos.

Cabe aclarar que el público meta del PEM son los y las estudiantes de las diferentes carreras impartidas en la Universidad, usuarios que bien podrían presentar alguna condición o necesidad especial de aprendizaje que obliga al programa a pensar en las distintas posibilidades de acceso y uso de sus multimedias educativos.

En lo referente a la implementación de los conceptos anteriormente definidos en la producción de multimedia educativo, cabe señalar que su uso depende del cumplimiento de criterios de selección, entre ellos la pertinencia pedagógica con respecto a los contenidos, o bien, el uso de los dispositivos móviles por parte del estudiantado.

Hoy más que nunca la portabilidad y el uso de variados dispositivos plantea interrogantes importantes en cuanto a producción y diseño que se tratan de responder desde la investigación, experimentación, implementación y posterior evaluación de la propuesta. Como ejemplo de lo anterior, y en el marco de la incursión de los diferentes conceptos expuestos en este ensayo, en el PEM se han elaborado dos materiales que marcaron el inicio de la implementación de las metodologías abordadas.

En el año 2013 se produjo Métodos numéricos para la enseñanza de la Matemática. En esta primera experiencia se presentó un multimedia educativo que sirve de apoyo al libro Métodos Numéricos para la Enseñanza publicado por la Editorial de la Universidad Estatal a Distancia (EUNED) de Costa Rica y que se utiliza en el curso Métodos Numéricos, que imparte el Programa Enseñanza de la Matemática bajo modalidad a distancia. El material ofrece, a la persona estudiante, la solución de ejemplos por medio de software libre y gratuito para la resolución de problemas y ejercicios en temas relacionados con la Teoría del error, Métodos de aproximación para soluciones de ecuaciones no lineales, Aproximación polinomial para valores de funciones y Aproximaciones en derivación e integración utilizando diversas técnicas y métodos.

La metáfora pedagógica desarrollada se elaboró bajo el concepto de un mapa de estrategia que propone cuatro escenarios que representan las áreas temáticas mencionadas. La propuesta se seleccionó porque mantiene una estrecha relación con las áreas del 
conocimiento expuestas y porque presenta similitud con los mapas estratégicos utilizados comúnmente en videojuegos de estrategia, que son de gran aceptación y reconocimiento por parte del público meta del material. A continuación, se muestra la propuesta gráfica de la portada y los módulos de contenido del material:

Figura 1: Portada del multimedia educativo Métodos numéricos para la enseñanza de la Matemática.

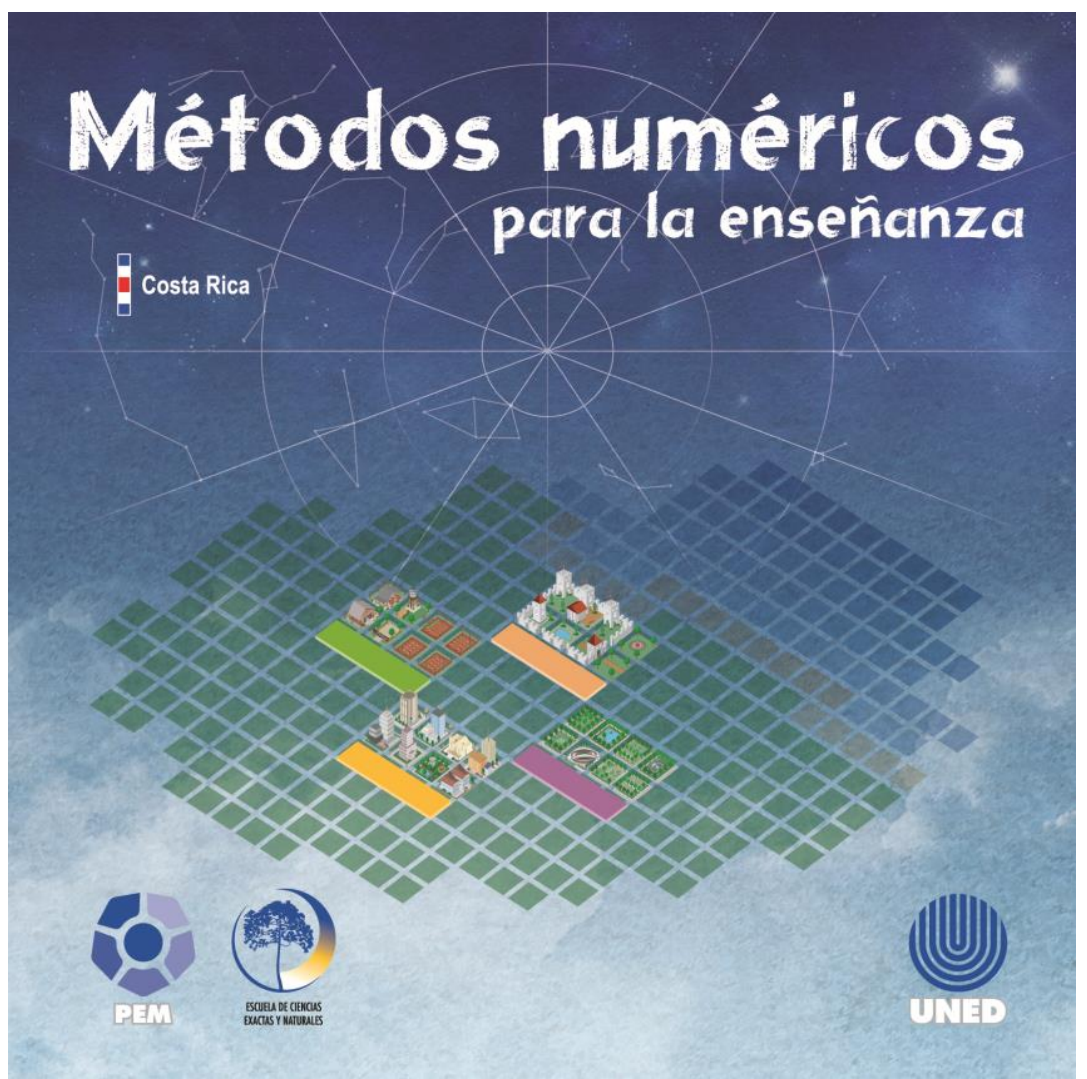

Fuente: Universidad Estatal a Distancia de Costa Rica y Programa de Producción Electrónica Multimedial (s.f.a). 
Figura 2: Módulos de contenido del multimedia educativo Métodos numéricos para la enseñanza

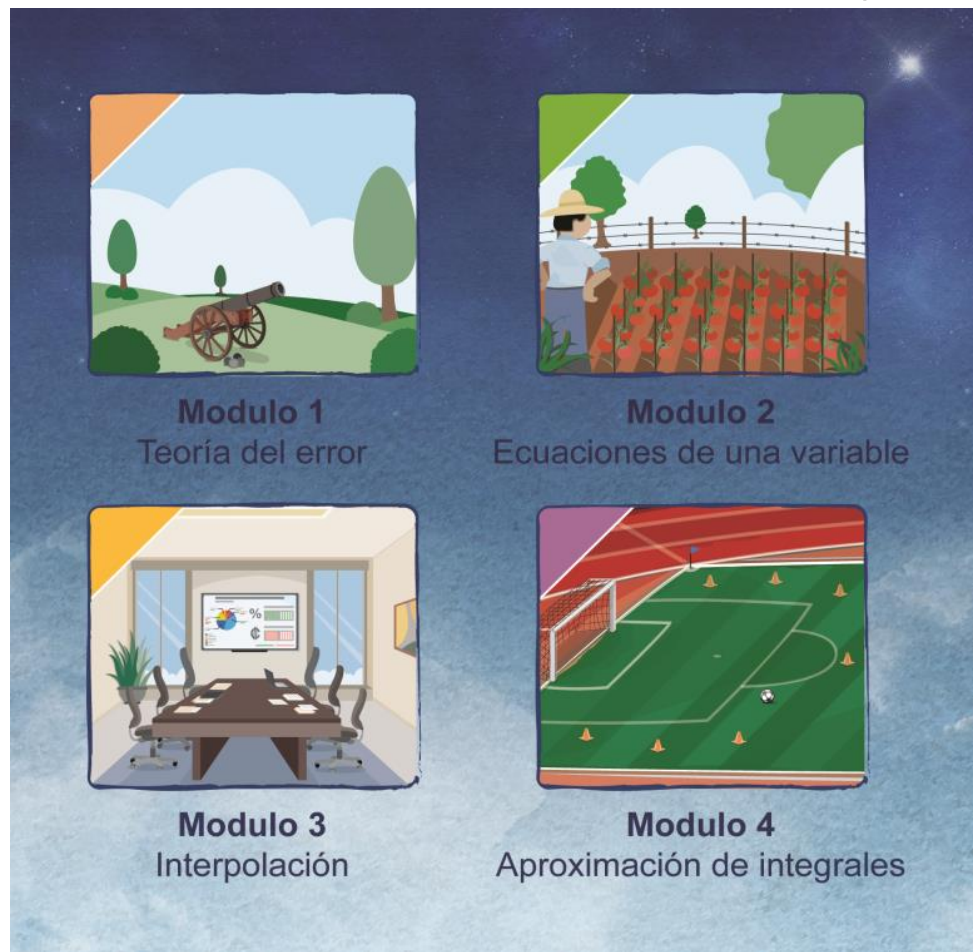

Fuente: Universidad Estatal a Distancia de Costa Rica y Programa de Producción Electrónica Multimedial (s.f.a).

La interfaz gráfica se elaboró en HTML5 con diseño adaptativo, por esta razón los diferentes elementos gráficos, de navegación, menús y recursos del material están concebidos de forma modular, independientes y adaptables, dispuestos en un plano cartográfico que, de igual manera, se adapta según la resolución de pantalla del dispositivo desde el que se accede.

El diseño gráfico del multimedia educativo se diseñó a partir de la concreción de la metáfora pedagógica y es una representación visual de esta, justificada pedagógicamente y elaborada a partir de la composición equilibrada y agradable de imágenes mapa de bits e ilustraciones vectoriales inspiradas, como se mencionó anteriormente, en los videojuegos de estrategia que utilizan isométricos para ambientar sus escenarios. Este material cuenta con algunos aportes del diseño universal aplicados en un contexto educativo como uso equiparable, flexible, intuitivo y simple. Se consideran, además, aspectos importantes de accesibilidad e inclusión como la posibilidad de ampliar, disminuir y restablecer el tamaño del texto en el contenido. 
Esta primera experiencia sirvió como base para el establecimiento de ciertos criterios de producción en este tipo de materiales didácticos como: contemplar la adaptabilidad del material desde el inicio de la producción, considerar, en el diseño de la metáfora pedagógica, aspectos que implica el diseño adaptativo, la simplicidad en el diseño gráfico que se debe utilizar en la elaboración de la interfaz gráfica y los diferentes recursos audiovisuales, entre otros.

Con la intensión de continuar la producción de multimedia educativo bajo las metodologías desarrolladas y adoptadas en el PEM a partir de experiencias previas, en el año 2015 se produjo Geometría Euclídea. Esta segunda experiencia presenta un material didáctico utilizado en los cursos de Geometría Euclídea y Construcciones geométricas que imparte el Programa Enseñanza de la Matemática bajo modalidad a distancia. Fue producido bajo el concepto de laboratorio virtual y se compone de cuatro laboratorios que le permiten al estudiantado y futuro docente de la Universidad aprender a realizar construcciones geométricas a partir de la técnica de Regla y compás, Portasegmentos, Doblado de papel y Software matemático.

La metáfora pedagógica se elaboró en torno a un vivero, se tomó en consideración el trasfondo histórico y teórico de la geometría, su clara percepción en la naturaleza desde la antigüedad, así como, la manifestación cotidiana de elementos geométricos que rodean al ser humano; por ejemplo: los puntos, los planos, las líneas rectas, curvas, entre otros. A continuación, se muestra la propuesta gráfica de la portada y los laboratorios virtuales del material: 
Figura 3: Portada del multimedia educativo Geometría Euclídea

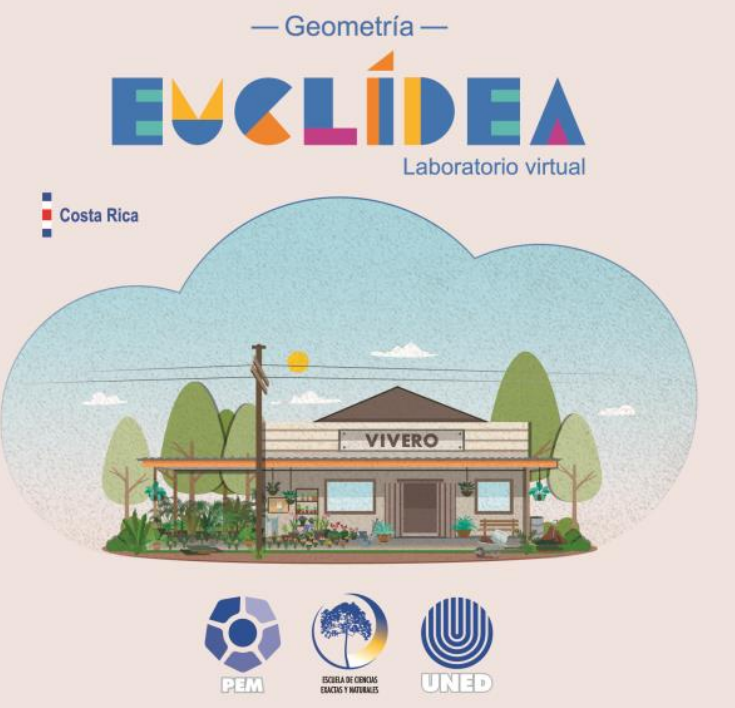

Fuente: Universidad Estatal a Distancia de Costa Rica y Programa de Producción Electrónica Multimedial (s.f.b).

Figura 4: Laboratorios virtuales del multimedia educativo Geometría Euclídea

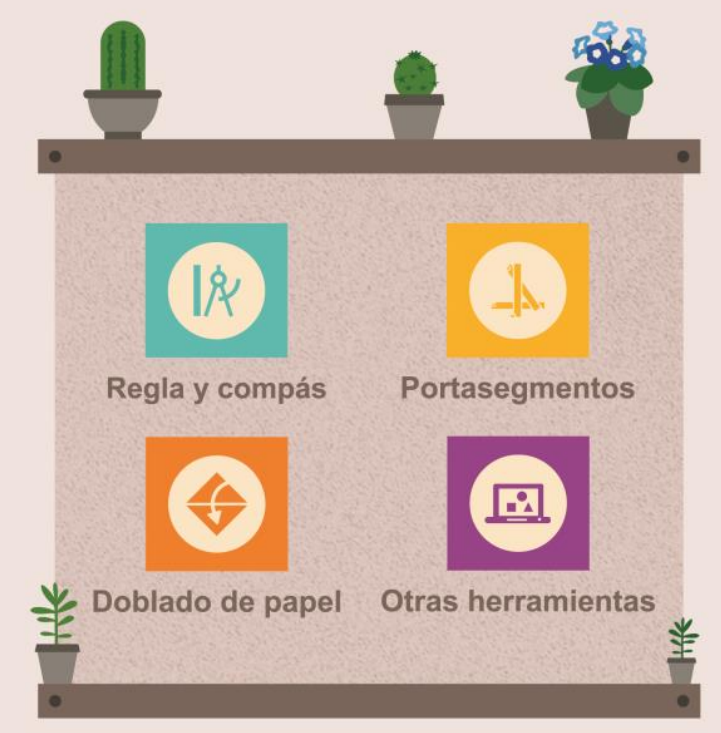

Fuente: Universidad Estatal a Distancia de Costa Rica y Programa de Producción Electrónica Multimedial (s.f.b).

La interfaz gráfica se elaboró en HTML5 con diseño adaptativo, por este motivo los diferentes elementos gráficos, de navegación, menús y recursos multimedia están concebidos de forma modular, independientes, escalables y adaptables, presentados en varios estantes de exhibición de plantas. 
El diseño gráfico del multimedia educativo se elaboró a partir de la concreción de la metáfora pedagógica y es una representación visual justificada pedagógicamente y diseñada a partir de una composición equilibrada y agradable, de ilustraciones vectoriales, inspiradas como se mencionó anteriormente, en ambientes cotidianos de un vivero con el objetivo de reforzar la temática general del material con el contexto en que se presentan los contenidos.

De igual manera, este recurso cuenta con algunos aportes del diseño universal, como su uso equiparable, flexible, información perceptible y tolerancia al error, aplicados en el ámbito educativo, y que también consideran aspectos importantes de accesibilidad e inclusión.

Estos dos ejemplos de multimedia educativo, producidos en el PEM, aunados a esfuerzos de investigación y capacitación a nivel interno del programa, son los primeros pasos hacia el desarrollo de nuevos materiales didácticos más accesibles e inclusivos, como el reciente desarrollo de los laboratorios virtuales para el aprendizaje, que tienen como fin seguir poniendo a disposición del estudiantado materiales de calidad que apoyen sus procesos de aprendizaje a distancia y en congruencia con las nuevas posibilidades tecnológicas, especialmente de formato y medios de reproducción.

\section{Conclusiones}

A partir de las experiencias generadas desde el PEM, así como de valoraciones recibidas de otras instancias académicas de la Universidad con las que se ha trabajado en conjunto, se presentan algunos factores a considerar a la hora de emprender una producción de multimedia educativo que contemple algunos de los principios de diseño desarrollados con anterioridad:

El diseño adaptativo demanda una mayor reflexión a la hora de planificar y concretar la propuesta gráfica y la disposición de contenidos porque se deben contemplar nuevos escenarios y posibilidades en la visualización de los multimedia educativos en tabletas y en teléfonos inteligentes. Eso no implica el sacrificio total o parcial de la gráfica y los contenidos, dado que dichos elementos se vinculan entre sí, independientemente de la resolución de pantalla del dispositivo. Por lo anterior, en los últimos 5 años el programa ha estado revisando, periódicamente, los procesos de producción y flujos de trabajo con el propósito de responder a las necesidades actuales de contenidos más accesibles e inclusivos.

El diseño de la interfaz gráfica debe conceptualizarse en una única propuesta, simple, concreta, escalable y adaptable para hacer más eficiente su proceso de elaboración. Este 
cambio de paradigma obligó a replantear el flujo de trabajo en diseño, ya que se pasó de elaborar varias versiones de una interfaz según la resolución de pantalla del dispositivo a concentrar los esfuerzos en una única propuesta, centrada en los elementos y acciones más importantes de navegación, lo cual contribuyó a mejorar tanto la experiencia como la usabilidad del material, pues todos sus elementos gráficos y de contenido se adaptan.

El diseño universal aplicado en la interfaz converge con el diseño adaptativo en la concreción de propuestas que evidencien accesibilidad e inclusión en armonía con la gráfica ya que los materiales están orientados a los y las estudiantes y de ellos depende el impacto que puede tener lo que se diseñe. Por lo anterior, el diseño gráfico es valorado desde una perspectiva pedagógica que permite generar empatía y motivación para explorar los contenidos. Bajo esa premisa, el PEM está en constante investigación de nuevas metodologías que contribuyan a mejorar la mediación de los contenidos, así como la experiencia visual de la interfaz gráfica de los materiales que desarrolla.

Los multimedia educativos se deben producir en función de las necesidades y capacidades del estudiantado, por lo tanto, es necesario un mayor análisis del público meta, con especial énfasis en acceso y tipo de dispositivos, así como la forma en que los utilizan para acceder a los materiales, esto permitirá, seleccionar los medios y elementos gráficos que realmente contribuyan a la mediación de los contenidos.

Es necesario, además, mejorar los procesos de evaluación de los multimedia educativos con el propósito de saber si las metodologías de diseño y producción utilizadas actualmente mejoran la accesibilidad e inclusión de los materiales disponibles para el estudiantado como apoyo en sus procesos de aprendizaje a distancia.

\section{Referencias}

Burgstahler, Sheryl. (2007). Universal Design in Education: Principles and Applications. Recuperado de http://www.washington.edu/doit/Brochures/Academics/ud edu.html

Díaz, Luis Fernando. (2011). Principios sobre la metáfora pedagógica. Recuperado de http://www.luisfernandodiaz.com/?p=105

Fornasari de Menegazzo, Lilia. (1994). Didáctica de la imagen. Zaragoza: Editorial Latina.

Fundación SIDAR. (2007). Principios del diseño universal. Recuperado de http://www.sidar.org/recur/desdi/usable/dudt.php

Gilliam Scott, Robert. (1980). Fundamentos del diseño. Buenos Aires: Editorial U. Leru. 
Gutiérrez, Favio. (2012). Principios fundamentales de la tipografía. Recuperado de http://www.faviogutierrez.com/category/tipografia/

Mañas, Moisés. (2011). Interfases. Reglas/teóricas. Recuperado de http://personales.upv.es/moimacar/master/download/interfaces.pdf

Misischia, Bibiana. (3 de setiembre de 2013). Supresión de barreras en la universidad. Página12, Recuperado de http://www.pagina12.com.ar/diario/universidad/10-2281342013-09-03.html

Morton, Jill. (2010). Why color matters. Recuperado de http://www.colorcom.com/research/why-color-matters

Observatorio de la Accesibilidad. (s.f.). Breve historia. Recuperado de http://www.observatoriodelaaccesibilidad.es/accesibilidad/breve-historia/

Organización de las Naciones Unidas para la Educación, la Ciencia y la Cultura - Unesco. (2013). Directrices para las Políticas de Aprendizaje Móvil. Recuperado de http://unesdoc.unesco.org/images/0021/002196/219662S.pdf

Rand, Paul. (2007). Design form and chaos. Massachusetts: Rockport Publishers, Inc.

Real Academia Española. (2001). Imagen. En Diccionario de la lengua española (22a. ed.). Recuperado de http://dle.rae.es/?id=KzwDY4y

Rubio, Manuel. (1 de setiembre de 2013). ¿Qué es Diseño Adaptativo? Recuperado de https://magazine.joomla.org/es/ediciones-anteriores/sept-2013/item/1514-que-esdiseno-adaptativo

Salazar Bejarano, Ana Gabriela, Berrocal Carvajal, Viviana, Salas Campos, lleana y Valerio Álvarez, Cinthya. (2014). Propuesta para el desarrollo de una aplicación para la gestión administrativa en la UNED, Costa Rica. Revista Innovaciones Educativas, 16(21), 1-11.

Shneiderman, Ben. (1998). Designing the user interface: Strategies for effective humancomputer interaction. Massachusetts: Addison-Wesley, Pub Co.

Universidad Estatal a Distancia de Costa Rica y Programa de Producción Electrónica Multimedial. (s.f.a). Geometría Euclidea. Recuperado de http://repositorio.uned.ac.cr/multimedias/geometria euclidea/index.html

Universidad Estatal a Distancia de Costa Rica y Programa de Producción Electrónica Multimedial. (s.f.b). Métodos numéricos para la enseñanza. Recuperado de http://repositorio.uned.ac.cr/multimedias/metodos numericos ensenanza

Velasco Santos, Perla, Laureano Cruces, Ana Lilia, Mora Torres, Marta y Herrera Bautista, Miguel Ángel. (octubre, 2010). Diseño de agentes pedagógicos a partir de los estilos de aprendizaje; una perspectiva a través del color. Ponencia presentada en el IV Congreso Mundial de Estilos de Aprendizaje. Recuperado de http://kali.azc.uam.mx/clc/02 publicaciones/material/Dise\%C3\%B10 de AvataresPers pColor 10.pdf 